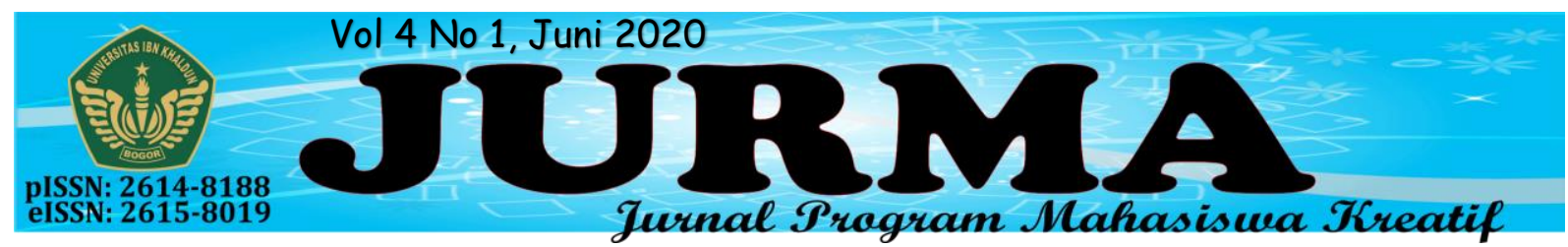

\title{
SOSIALISASI PENDIDIKAN STOP AKSI BULLYING
}

\author{
Muhammad Zenuri Ikhsan ${ }^{1}$, Eska Perdana Prasetya ${ }^{2}$, Nuraeni $^{3}$ \\ muhamadzanurii@gmail.com ${ }^{1}$ \\ eska@uika-bogor.ac.id ${ }^{2}$ \\ nuraeni@uika-bogor.ac.id ${ }^{3}$ \\ Fakultas Hukum Universitas Ibn Khaldun ${ }^{1}$, Fakultas Keguruan dan Ilmu Pendidikan Universitas Ibn Khaldun ${ }^{2,3}$
}

\begin{abstract}
ABSTRAK
Mensosialisasikan kepada anak anak di desa ciaruteun udik untuk memberikan pengetahuan yang penting tentang bahayanya aksi bullying yang tengah dihadapi bangsa Indonesia, khususnya di desa desa terpencil. Perilaku bullying di lingkungan sekolah dapat menciptakan suasana lingkungan yang kurang mendukung terhadap perkembangan siswa, baik dalam bidang akademik maupun bidang sosial. Perilaku bullying dapat menyakiti siswa, sehingga mereka merasa tidak diinginkan dan ditolak oleh lingkungannya. Hal ini tentunya akan membawa efek kepada berbagai kegiatan siswa disekolah. Aksi bullying terbagi dalam 3 bentuk perilaku, yakni secara fisik (menjegal, menjambak, menendang, memukul, hingga memegang alat kelamin), verbal (berkata kasar, memaki, berkata kasar, mengolok olok, mengejek, berkata hal hal yang jorok), dan psikologis (membuat seolah olah temannya bersalah dan dirty looks). Pelaku bullying memiliki postur tubuh yang tinggi dari teman temannya, temperamen dan sering bertindak fisik. Maka dari itu saya sebagai penulis membuat judul "sosialisasi stop aksi bullying". Program sosialisasi ini menggunakan pendekatan dalam bentuk penyuluhan, serta sasarannya ke siswa siswi sdn ciaruteun udik 02 .
\end{abstract}

\section{Kata Kunci: Bullying, Sosialisasi, Psikologis}

\section{PENDAHULUAN}

\section{Latar Belakang}

Bullying adalah fenomena yang telah lama terjadi di kalangan anak dibawah umur. Kasus bullying biasanya menimpa anak sekolah. Pelaku bullying akan mengintimidasi/mengejek kawannya sehingga kawannya tersebut jengkel. Atau lebih parah lagi, korban bullying akan mengalami depresi dan hingga timbul rasa untuk bunuh diri. Bullying harus dihindari karena bullying mengakibatkan korbannya berpikir untuk tidak berangkat ke sekolah karena di sekolahnya ia akan di bully oleh si pelaku. Selain itu, bullying juga dapat menjadikan seorang anak turun prestasinya

karena merasa tertekan sering di bully oleh pelaku.

Sekalipun bullying telah menjadi sebuah masalah selama berabadabad, bullying tidak menerima perhatian penelitian signifikan sampai tahun 1970-an (Olweus, 1978). Profesor Dan Olweus adalah ilmuwan pertama yang memfokuskan diri pada topik tersebut dan mengkontribusikan data ilmiahnya pada literatur bullying. Banyak penelitian Olweus menjelaskan mengapa beberapa anak melakukan bullying dan mengapa beberapa lainnya menjadi korban bullying. Bukan itu saja, Olweus juga menunjukkan 
bahwa bullying di sekolah dapat direduksi secara signifikan. Hal ini merupakan pencapaian yang sangat penting.

Hasil studi dari Olweus mengesankan banyak peneliti sosial di dunia. Sebelum abad ke -20 berakhir, ratusan studi serupa telah dilakukan di banyak negara. Buku, artikel, website, video dan CD mulai bermunculan dengan maksud untuk menjelaskan apa saja yang perlu kita lakukan untuk mereduksi bahkan menghentikan bullying di sekolah.

Dewasa ini sudah banyak terjadi kasus bullying di lingkungan sekolah dan kasus ini sudah banyak mendapat perhatian terutama dari orang tua pelaku dan korban, pihak sekolah, bahkan dari pemerintah. Hal ini perlu dibahas dan diketahui lebih lanjut, karena kita ada dalam lingkaran pendidikan yang akan menemukan banyak masalah dari anak didik kita. Sebagai bahan pertimbangan itu, saya mengambil kasus ini sebagai pokok permasalahan dari makalah ini.

Sebagai sebuah hak yang hakiki maka pengaturan mengenai hak atas pendidikan diatur dalam Alinea Keempat

\section{METODOLOGI}

Metode penelitian yang digunakan adalah metode penelitian eksperimen, yaitu metode penelitian yang digunakan untuk

\section{REALISASI PROGRAM}

Kegiatan sosialisasi stop aksi bullying dilakukan pendekatan dalam bentuk penyuluhan melalui media infokus. Sasarannya adalah siswa sd kelas 5 dan 6 . Seluruh peserta berjumlah 90 orang yang semuanya berumur $11-12$ tahun. Kegiatan sosialisasi stop bullying ini berlangsung dengan mengedukasi bentuk prilaku bullying serta hal hal yang harus
Pembukaan dan Pasal 31 Undang-Undang Dasar 1945 Amandemen Ke-4. Berdasarkan hal tersebut maka ditegaskan bahwa, salah satu tujuan dari pembentukkan negara Indonesia adalah untuk mencerdaskan kehidupan bangsa. Kecerdasan kehidupan berbangsa dan bernegara baru dapat tercapai melalui pemberian suatu pendidikan yang terintegrasi dan disesuaikan dengan kebutuhan setiap warga negara. Pengaturan hak atas pendidikan telah diatur dalam Pasal 31 Undang-Undang Dasar 1945 ayat (1) dimana disebutkan bahwa, "Setiap orang berhak untuk mendapatkan pendidikan". Pasal tersebut bermakna bahwa negara berkewajiban memenuhi hak atas pendidikan bagi setiap warga negaranya, tanpa terkecuali atau membedakan suku, ras, agama, atau bahkan keadaan sosial dan ekonominya. Hal inilah yang menjadi dasar bahwa setiap anak di Indonesia memiliki hak yang sama untuk mendapatkan pendidikan yang layak, dan berhak mengembangkan diri sebebas-bebasnya.

mencari pengaruh perlakuan tertentu terhadap yang lain dalam kondisi yang terkendalikan (Sugiyono, 2010).

dilakukan untuk mencegah bentuk perilaku bullying kemudian diakhir pertemuan anak anak yang mengikuti kegiatan tersebut diberikan sejumlah pertanyaan seputar stop bullying yang apabila berhasil menjawab pertanyaannya, maka akan dapat hadiah berupa souvenir. Di acara ini yang menjadi pemateri yaitu Pak Aryo Sarjono S. Pi menjabat sebagai anggota DPRD. 
Sedangkan yang menjadi narasumber saya sendiri, Muhamad Zenuri Ikhsan. Dan yang memfasilitasi dibantu oleh seluruh anggota KKN kelompok 23. dilaksanakan pada hari Jumat tanggal 30 Agustus 2018 bertempat di ruang kelas 6 sdn ciaruteun udik 02 jalan raya layung sari RT 03/RW $06 \mathrm{Kp}$. Layung Sari Ds. Ciaruteun Udik Kec. Cibungbulang Kab. Bogor. Selama sekitar pukul 09:30 - 12:30.

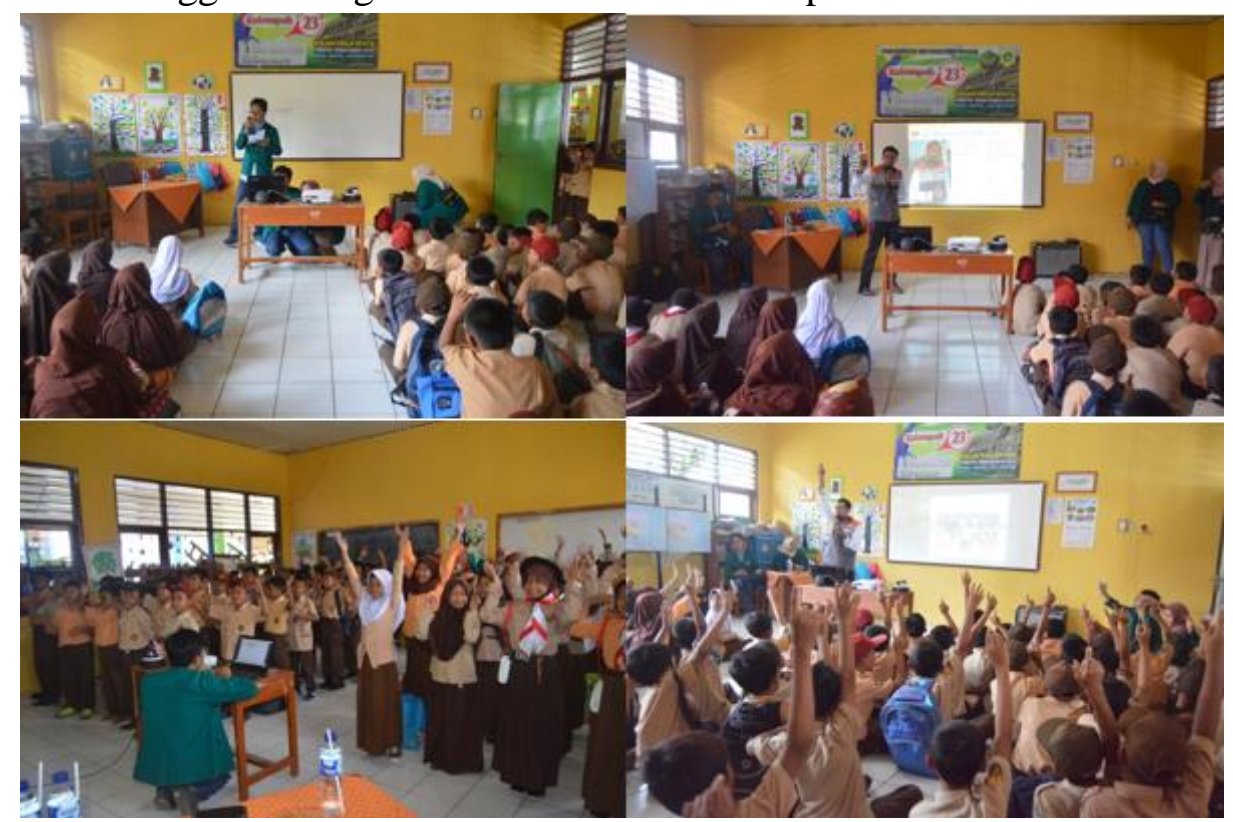

Hasil yang dicapai dalam sosialisasi anti bullying ini adalah anak anak mengetahui bahwa bullying merupakan salah satu tindak pidana dengan diadakannya sosialisasi ini anak anak dapat mengerti kriteria-kriteria yang termasuk

\section{KESIMPULAN}

Untuk pihak sekolah sangat apresiasi dan antusias dengan diadakannya kegiatan sosialisasi ini. Dan harapan kita tidak hanya sekolah sdn ciaruteun udik 02 saja tapi sekolah di seluruh indonesia dapat bullying, aturan hukumnya, sanksi pidananya serta contoh dari kasus kasus bullying. Tujuannya agar anak anak tidak melakukan bullying antar sesamanya sehingga tidak merugikan diri sendiri dan orang lain.

menjaga lingkungan yang aman dan nyaman sebagai salah satu belajar anak. Karna tanpa kita sadari, bullying merupakan salah satu penghambat anak untuk belajar dan berkembang. 


\section{DAFTAR PUSTAKA}

Prasetya, E. (2020). 10 Characteristics of SMK Teachers in the Industrial Era 4.0 (Case Study at SMK Bina Profesi Bogor). Edumaspul: Jurnal Pendidikan, 4(1), 5055.

https://doi.org/10.33487/edumaspul.v4i1 .297

Sugiyono. 2010. Metode Penelitian Pendidikan Pendekatan Kuantitatif, kualitatif, dan R\&D. Bandung: Alfabeta

http://hamzahizers.blogspot.com/2017/06/p engaruh-bulliying-terhadapgenerasi.html

https://www.researchgate.net/publication/3 12161296_Kasus_Kekerasan_pada_ Anak_Sekolah_School_Bullying 